\title{
NEURONAL CELL SURFACES: DISTINCTIVE GLYCOPROTEINS OF CULTURED ADRENERGIC AND CHOLINERGIC SYMPATHETIC NEURONS ${ }^{1}$
}

\author{
SARAH J. BRAUN, KA'THLEEN J. SWEADNER, ${ }^{2}$ AND PAUL H. PA'T'TERSON \\ Departmenl of Neurobiology, Harvard Medical School, Boston, Massachusells 02115
}

\begin{abstract}
Cell surface components which are candidates for a role in nerve-target interactions specific for neurons of particular transmitter types in the sympathetic nervous system have been identified. Neurons of superior cervical ganglia of neonatal rats were dissociated and cultured in the virtual absence of non-neuronal cells under conditions previously found to control their choice of neurotransmitter. When raised in medium conditioned by heart cells, the neurons become cholinergic; when raised in medium which depolarizes them, the neurons remain in their original adrenergic state. The cell surface proteins of the neurons were labeled by either metabolic or surface-specific methods, separated by two-dimensional polyacrylamide gel electrophoresis, and visualized by autoradiography. A total of approximately 35 glycoproteins can be resolved, of which at least 14 are exposed on the cell surface. We evaluated glycoproteins of neurons raised under conditions which differ in their potency for inducing cholinergic properties: medium conditioned by skeletal muscle, liver, or heart cells or medium containing $1 \mathrm{~mm}$ butyric acid. The expression of three neuronal glycoproteins was correlated with the ability of a given culture condition to induce the synthesis and accumulation of acetylcholine or catecholamines. Two of these proteins are exposed on the cell surface, and the third appears to be identical with a protein previously shown to be secreted into the culture medium.
\end{abstract}

Among the outermost molecules of the cell surface, glycoproteins are likely to interact with the extracellular environment during development and thus are candidates for involvement in cell-cell and cell-environment interactions (Denburg, 1978a; Frazier and Glaser, 1979). In the nervous system, both nonspecific and homotypic adhesion factors have been described as well as glycoprotein and glycolipid gradients which can be correlated with maps of positional information in the retina and tectum (Barondes, 1976; Gottlieb and Glaser, 1980; Trisler et al., 1981). Biochemically defined mediators of specific interactions between classes of neurons and appropriate target cells are still being sought (Denburg, 1978b).

A system which may prove useful in the identification of the glycoproteins of interest and the elucidation of their roles in synapse formation is that of the dissociated cell culture of sympathetic neurons. These neurons can

\footnotetext{
${ }^{1}$ This work was supported by National Institute of Neurological and Communicative Disorders and Stroke, Wellington Fund, and Rita Allen Foundation grants to P. H. P. K. J. S. was supported by fellowships from The Medical Foundation/Charles A. King Trust and the Muscular Dystrophy Association. We wish to thank Doreen McDowell, Geraldine Spencer, Shirley Wilson, and Joe Gagliardi for assistance with the cell culture and with the preparation of the manuscript.

${ }^{2}$ To whom correspondence should be addressed.
}

form cholinergic or adrenergic synapses on one another or on a variety of non-neuronal target cells (Bunge et al., 1978; Patterson, 1978). The choice of synapse formed by these neurons can be controlled through use of a factor(s) produced by certain non-neuronal cells (Patterson and Chun, 1977; Hawrot, 1980; Weber, 1981), depolarization of the neurons (Walicke et al., 1977), and $\mathrm{Ca}^{2+}$ and cyclic nucleotide effectors (Walicke and Patterson, 1981a, b). Furthermore, these neurons can be grown in the virtual absence of non-neuronal cells, facilitating biochemical analysis.

Prior work has shown that the cholinergic and adrenergic sympathetic neurons spontaneously release into the medium characteristic glycoproteins, some of which are correlated with the transmitter status of the neurons (Sweadner, 1981). There is also evidence for differences in the surfaces of the two types of neurons: a monoclonal antibody has been produced which binds more to the surfaces of the adrenergic neurons than of the cholinergic neurons (Chun et al., 1980), and the lectin soybean agglutinin binds at a 5-fold higher density to the adrenergic axonal surfaces than to the cholinergic axonal surfaces (Schwab and Landis, 1981). The soybean agglutinin binding may reflect a difference between the two neuronal types in the accessibility or amount of the glycolipid, globoside (Zurn and Patterson, 1981). In order to search 
systematically for glycoprotein differences between the surfaces of the adrenergic and cholinergic sympathetic neurons, we have labeled these components of the cultured cells by metabolic and surface-specific methods. Two-dimensional polyacrylamide gel electrophoresis followed by autoradiography shows a correlation between the transmitter phenotype and certain of the surface glycoproteins.

\section{Materials and Methods}

\section{Preparation of neurons}

Dissociated sympathetic neurons were prepared by the mechanical procedure previously described by Hawrot and Patterson (1979). All neurons received unmodified $\mathrm{L} 15 \mathrm{CO}_{2}$ medium for the first 3 days in culture. On day 4 , neurons received their first change of modified medium: $50 \%$ medium conditioned by heart, liver, or skeletal muscle cells; $20 \mathrm{~mm} \mathrm{~K} \mathrm{~K}^{+}$medium; or $1 \mathrm{~mm}$ butyric acid medium. On days 4 and 8 , neuronal cultures were treated with $10 \mu \mathrm{M}$ cytosine arabinoside to kill non-neuronal cells. The medium was changed every other day, and cultures were used when 3 to 4 weeks old. Saturating amounts of nerve growth factor $(7 \mathrm{~S})$ were present in all experiments.

\section{Preparation of conditioned medium}

Primary cell cultures of non-neuronal cells from neonatal rats were prepared as described by Patterson and Chun (1977), but horse serum was substituted for fetal calf serum. Hepatocyte and skeletal muscle cultures were preplated to reduce the number of fibroblasts. Hepatocytes were dissociated with $1 \mathrm{mg} / \mathrm{ml}$ of collagenase (Worthington), allowed to settle in tissue culture flasks for 12 to $18 \mathrm{hr}$, and then removed by gentle trituration. The cells were replated at a density of 1 to $3 \times 10^{6}$ cells into collagen-coated 60-mm Petri dishes (Hawrot and Patterson, 1979). Cells from pectoral skeletal muscle also were treated with collagenase and allowed to settle for 12 to $18 \mathrm{hr}$ in flasks. The flasks were incubated in trypsin (Worthington, $1 \mathrm{mg} / \mathrm{ml}$ in calcium, magnesium-free phosphate-buffered saline as prepared by Gibco) and monitored with a microscope. Myoblasts were collected and removed before most of the fibroblasts began to detach from the flask surface. The cells were washed three times with serum-containing $\mathrm{L} 15 \mathrm{CO}_{2}$ medium to remove the trypsin and replated at a density of $1.25 \times 10^{6}$ cells in 60 $\mathrm{mm}$ collagen-coated Petri dishes. Irradiation with ${ }^{60} \mathrm{Co}$ to arrest mitosis after the culture had grown to confluency further reduced the final proportion of fibroblasts. When the non-neuronal cells achieved confluency, the cultures were washed with serum-free medium and grown in medium which usually contained $5 \%$ rat serum but which, in some experiments, was supplemented with epidermal growth factor, insulin, transferrin, and bovine serum albumin, as described by Fukada (1980), instead of rat serum. The medium was collected every other day, supplemented with fresh vitamin mix and $7 \mathrm{~S}$ nerve growth factor (Hawrot and Patterson, 1979), centrifuged at 700 $\times g$ for 3 min to remove detached cells and debris, divided into aliquots of 3 to $5 \mathrm{ml}$, and frozen. This conditioned medium was mixed with an equal volume of fresh medium just before being given to the neurons.

\section{Metabolic labeling of neuronal proteins}

Neuronal cultures in wells containing about $50 \mu \mathrm{l}$ were labeled for $20 \mathrm{hr}$ with 30 to $50 \mu \mathrm{M} \mathrm{L}-\left[5,6-{ }^{3} \mathrm{H}\right]$ fucose, 60.0 $\mathrm{Ci} / \mathrm{mmol}$; $\mathrm{D}-\left[1,6-{ }^{3} \mathrm{H}(\mathrm{N})\right] \mathrm{glucosamine}, 39.6 \mathrm{Ci} / \mathrm{mmol}$; $\mathrm{D}-[1-$ $\left.{ }^{3} \mathrm{H}(\mathrm{N})\right]$ galactose, $14.2 \mathrm{Ci} / \mathrm{mmol}$; or $\mathrm{L}-\left[4,5-{ }^{3} \mathrm{H}(\mathrm{N})\right]$ leucine, $51.6 \mathrm{Ci} / \mathrm{mmol}$ (New England Nuclear) as described previously (Sweadner, 1981). After incubation, the neurons were washed three times with basic salt solution (BSS; $132 \mathrm{mM} \mathrm{NaCl}, 5.4 \mathrm{~mm} \mathrm{KCl}, 1.26 \mathrm{mM} \mathrm{CaCl}_{2}, 1.8 \mathrm{~mm} \mathrm{MgCl}_{2}$, $15 \mathrm{~mm}$ HEPES (4-(2-hydroxyethyl)-1-piperazine-ethanesulfonic acid), $\mathrm{pH} 7.2$ ) to remove secreted proteins and unincorporated label, scraped from the dishes in the presence of the protease inhibitor phenylmethylsulfonyl fluoride (Sigma, $1 \mathrm{~mm}$ ), and prepared for gel electrophoresis as described below. All three sugars labeled the same glycoproteins as analyzed by one-dimensional gel electrophoresis in sodium dodecyl sulfate (SDS) (data not shown). $\left[{ }^{3} \mathrm{H}\right]$ Fucose gave the heaviest labeling of all of the sugars tested, and since it is not metabolized or incorporated into cellular components other than glycoprotein, it was employed routinely.

\section{Transmitter synthesis}

Neurotransmitter synthesis and storage from $\left[{ }^{3} \mathrm{H}\right] \mathrm{cho-}$ line and $\left[{ }^{3} \mathrm{H}\right]$ tyrosine precursors was measured as described previously (Mains and Patterson, 1973) and was generously performed by K. Fukada and E. Wolinsky (Harvard Medical School).

\section{External treatments}

Neuraminidase treatment. Cultures (50 to $100 \mu \mathrm{g}$ of protein) which had been incubated for 24 to $30 \mathrm{hr}$ in $\left[{ }^{3} \mathrm{H}\right]$ fucose were washed three times with BSS and then incubated for $1 \mathrm{hr}$ in $50 \mu \mathrm{l}$ of Clostridium perfringens neuraminidase (Sigma) in BSS at 0.25 to $1.0 \mathrm{unit} / \mathrm{ml}$.

Periodate treatment. A modification of the method of Van Lenten and Ashwell (1971) was used to label sialic acid. Cultures were incubated for $10 \mathrm{~min}$ at $0^{\circ} \mathrm{C}$ in $1 \mathrm{mM}$ $\mathrm{NaIO}_{4}$ in $154 \mathrm{mM} \mathrm{NaCl}, 5 \mathrm{~mm} \mathrm{KCl}$. After being quenched with glycerol (20 mM in BSS), the cultures were washed three times with BSS and treated with $\left[{ }^{3} \mathrm{H}\right] \mathrm{BH}_{4}, 300 \mu \mathrm{Ci}$ / culture (Amersham, 6 to $12 \mathrm{Ci} / \mathrm{mmol}$ ), in BSS, $\mathrm{pH} 10.0$, for 10 to $15 \mathrm{~min}$ at room temperature. After reduction, neurons were washed three times with $\mathrm{pH} 7.25 \mathrm{BSS}$ and prepared for gel electrophoresis.

Lactoperoxidase-catalyzed iodination. Iodination (Hubbard and Cohn, 1972) was performed in BSS with $5 \mathrm{~mm}$ glucose. Cultures were washed four times to remove serum and other medium constituents, chilled to $0^{\circ} \mathrm{C}$, and incubated for $15 \mathrm{~min}$ with $20 \mu \mathrm{g} / \mathrm{ml}$ of lactoperoxidase (Boehringer Mannheim, West Germany), 0.1 unit/ $\mathrm{ml}$ of glucose oxidase (Worthington/Millipore, Freehold, $\mathrm{NJ}$ ), and $100 \mu \mathrm{Ci} /$ well of carrier-free ${ }^{125} \mathrm{I}$ (New England Nuclear). The reaction was stopped by washing the cultures with BSS containing $\mathrm{NaI}$ instead of $\mathrm{NaCl}$.

Galactose oxidase treatment. Washed, neuraminidasetreated cultures were incubated in BSS containing 1.4 units/ml of galactose oxidase (Sigma) which had been purified by the method of Hatton and Regoeczi (1976). After $30 \mathrm{~min}$ in a $37^{\circ} \mathrm{C}$ air incubator, the cultures were washed three times with BSS and treated with $\left[{ }^{3} \mathrm{H}^{3} \mathrm{BH}_{4}\right.$. 


\section{Gel electrophoresis and photofluorography}

Cultures were solubilized in SDS and subjected either to one-dimensional gel electrophoresis (Laemmli, 1970) on slab gels with a linear gradient of 5 to $15 \%$ acrylamide or to two-dimensional electrophoresis in which isoelectric focusing in cylindrical gels was followed by slab gel electrophoresis in SDS (Ames and Nikaido, 1976). Isoelectric focusing gels were prepared as described by O'Farrell and O'Farrell (1976) with $2.0 \% \mathrm{pH} 3.5$ to 10 and $0.5 \% \mathrm{pH} 5$ to 7 Ampholines (LKB Instruments, Rockville, $\mathrm{MD}$ ), while NEPHGE (nonequilibrium $\mathrm{pH}$ gradient electrophoresis) gels were prepared as described by O'Farrell et al. (1977) with $1.2 \% \mathrm{pH} 7$ to 9 and $1.2 \% \mathrm{pH} 9$ to 11 Ampholines (LKB). Gel photofluorography was done by the method of Bonner and Laskey (1974), using preflashed Kodak XR-5 or XAR-5 film and DuPont Cronex Lighting-Plus intensifying screens to enhance the sensitivity. The optical density of autoradiographs was determined by scanning with a Schoeffel SD3000 spectrodensitometer. Sequential 3-mm swaths of the films were scanned, and the peaks of optical density were integrated by cutting out and weighing the area under the curve. The background of the region immediately above the area in question was subtracted from the weight of the peak of interest. The content of a given peak was normalized to the percentage of total optical density of the entire autoradiograph.

Molecular weights were calibrated with myosin and actin (prepared from skeletal muscle by $\mathrm{KCl}$ extraction), $\beta$-galactosidase, muscle phosphorylase, bovine serum albumin, and myoglobin (Sigma). These proteins were acetylated with $100 \mu \mathrm{Ci} / \mathrm{ml}$ of iodo $\left[{ }^{14} \mathrm{C}\right]$ acetic acid (New England Nuclear) in $5 \mathrm{~mm}$ pyrophosphate buffer, $\mathrm{pH} 8.2$, for $15 \mathrm{~min}$ at room temperature so that they could be detected on the autoradiograms.

\section{Results}

Comparison of neurons grown under adrenergic or cholinergic conditions. Sympathetic neurons were grown under adrenergic conditions (depolarization with elevated potassium) or cholinergic conditions (heart cellconditioned medium) for 3 to 4 weeks and were incubated with $\left[{ }^{3} \mathrm{H}\right]$ fucose or $\left[{ }^{3} \mathrm{H}\right]$ leucine for $20 \mathrm{hr}$. When subjected to two-dimensional electrophoresis, the fucose-labeled proteins of the adrenergic and cholinergic neurons displayed patterns different from each other and distinct from those of leucine-labeled neurons (Fig. 1). The most dramatic difference in the fucose-labeled proteins oc-
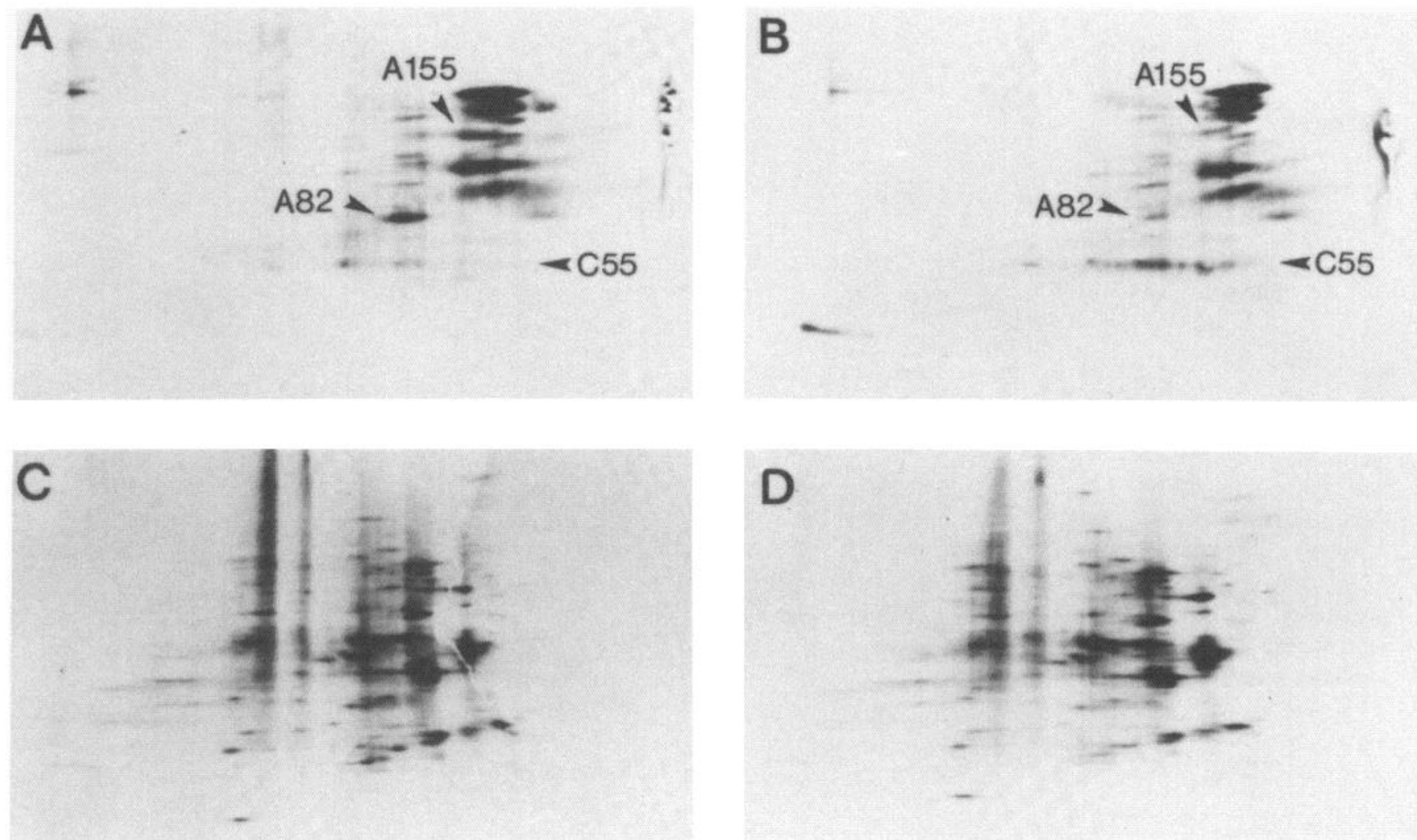

Figure 1. Two-dimensional gel analysis of neuronal proteins. The basic end of the gel is on the left and the acidic end is on tive right, and proteins are separated by molecular weight from top to bottom. In $A$ and $B$, the glycoproteins were labeled by metabolic incorporation of $\left[{ }^{3} \mathrm{H}\right]$ fucose, while in $C$ and $D$, all newly synthesized proteins were labeled by metabolic incorporation of $\left[{ }^{3} \mathrm{H}\right]$ leucine. The most abundant glycoproteins are more acidic than the average leucine-labeled proteins. $A$ and $C$, Adrenergic neuronal cultures; $B$ and $D$, cholinergic cultures. Those bands which differ reproducibly in adrenergic and cholinergic cultures are marked with arrowheads. At the extreme right of gels $A$ and $B$, where the SDS migrates in the isoelectric focusing dimension, there is an irregularly shaped spot labeled with $\left[{ }^{3} \mathrm{H}\right]$ fucose that may be either glycoprotein or glycolipid; neither its expression nor its shape was consistent from experiment to experiment. 
curred in a broad horizontal region (belt) with an apparent molecular weight of 55,000. The labeling of this region was found to be markedly increased in gels of cholinergic neurons compared with gels of adrenergic neurons and is named C55 (for cholinergic $/ M_{\mathrm{r}}=55,000$; Fig. $1 B$ ). This result was reproduced in pairs of adrenergic and cholinergic sister cultures from 15 separate platings. In contrast to the increased labeling of $\mathrm{C} 55$ in cholinergic neurons, there were two glycoproteins which were labeled more heavily in adrenergic neurons: one with an apparent molecular weight of 82,000 (A82) and one with an apparent molecular weight of 155,000 (A155; Fig. 1A). This result was reproduced for $\mathrm{A} 155$ in all 15 experiments and was reproduced for $\mathrm{A} 82$ in 14 out of 15 experiments.
Spectrodensitometric analysis of these autoradiographs showed that the C55 belt constituted relatively high percentages of the total optical density of the autoradiographs from 15 different platings of neuronal cultures grown in heart cell-conditioned medium (mean, 4.95\%; range, 2.74 to $7.7 \%$ ), while it constituted a much lower percentage of the total optical density of the autoradiographs from sister cultures grown in elevated potassium medium (mean, 0.27\%; range, undetectable to $0.97 \%$; Table I). A82 constituted 2.34\% (range, 1.2 to $3.3 \%$; 6 platings) of the total density of the autoradiographs derived from adrenergic cultures, while it was only $0.56 \%$ (undetectable to $1.18 \%$; 6 platings) of the total optical density of the autoradiographs from cholinergic cultures.

TABLE I

Culture conditions alter protein expression as well as transmitter choice

Different culture conditions were compared for their ability to alter neurotransmitter choice and the expression of the proteins C55 and A82. All cultures were maintained in the conditions shown for 3 weeks after the initial plating, and sister cultures were assayed for transmitter synthesis and protein expression. The abbreviations used in the table are: ACh, acetylcholine; $\mathrm{CA}$, catecholamine (norepinephrine plus dopamine); $\mathrm{CM}$, conditioned medium. Induction is the increase in the ACh/CA ratio compared to the value obtained in the most adrenergic condition (20 mM $\left.\mathrm{K}^{+}\right)$. $\mathrm{ACh}$ and $\mathrm{CA}$ are expressed in picomoles synthesized and accumulated per dish.

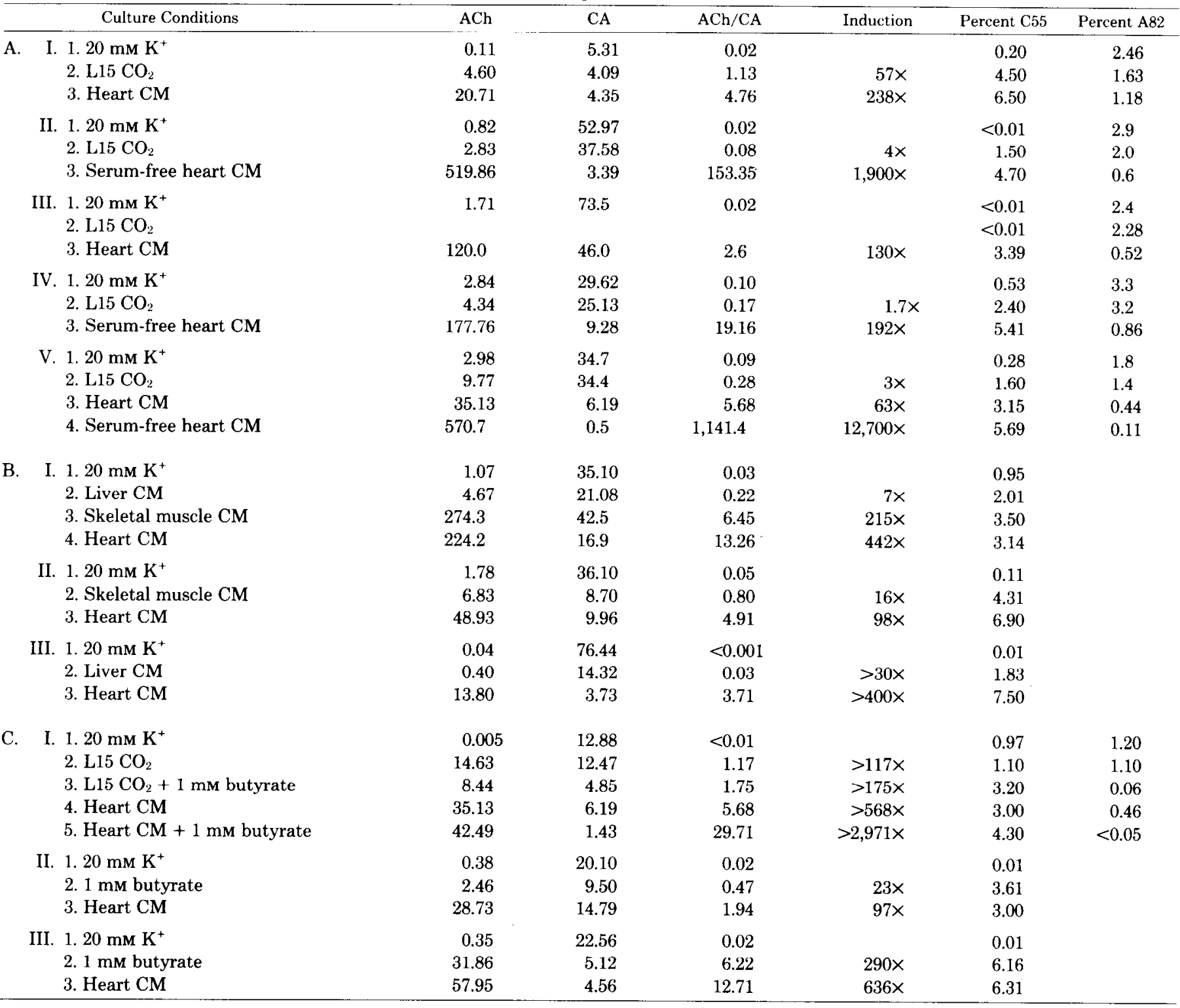


Because of its proximity to several other glycoproteins, A155 could not be resolved satisfactorily by densitometry. The diffuse focusing of most of the fucose-labeled glycoproteins is a reproducible characteristic. The majority of non-glycosylated proteins (Fig. 1, C and D) focused sharply under identical electrophoretic conditions.

The standard two-dimensional gel electrophoretic system shown in Figure 1 (isoelectric focusing followed by electrophoresis in SDS) resolves proteins with isoelectric points from $\mathrm{pH} 7$ to 4 . To detect glycoproteins with more basic isoelectric points, we separated identical samples of labeled proteins by nonequilibrium $\mathrm{pH}$ gradient electrophoresis (NEPHGE) followed by electrophoresis in SDS. The $\mathrm{pH}$ gradient was from 9.6 to 7.1. Although some quantitative differences in the expression of basic glycoproteins in adrenergic and cholinergic cultures are seen in Figure 2, $A$ and $B$, these differences were not reproducible. Much longer exposure times (8- to 10-fold) were required to visualize the $\left[{ }^{3} \mathrm{H}\right]$ fucose-labeled bands shown in Figure 2 than those shown in Figure 1, indicating that these few basic glycoproteins are minor or lightly glycosylated constituents of the glycoprotein class.

Protein expression and transmitter choice in different culture conditions. The culture conditions chosen above were those which optimize the expression of either adrenergic or cholinergic properties. By using other conditions, it is possible to obtain mature mass cultures with intermediate ratios of cholinergic and adrenergic properties, and these were examined for a correlation between protein expression and neurotransmitter choice. Neurons grown in unmodified $\mathrm{L} 15 \mathrm{CO}_{2}$ medium in the absence of non-neuronal cells or conditioned medium were predominantly adrenergic but did synthesize reproducibly higher amounts of acetylcholine than neurons grown in $20 \mathrm{mM}$ $\mathrm{K}^{+}$medium (Table I; Walicke et al., 1977). Such cultures were found in the present study to express C55, A82 (Table I $A$ ), and A155 (by visual inspection) at levels intermediate between those grown in $20 \mathrm{mM} \mathrm{K}^{+}$and those grown in heart cell-conditioned medium. Fukada (1980) has shown recently that heart cells will produce active conditioned medium factor in medium containing no serum but supplemented with insulin, epidermal growth factor, and transferrin. Such conditioned medium was observed here to give good induction of acetylcholine synthesis and suppression of catecholamine synthesis and a corresponding increase in expression of C55 and decrease in A82 (Table I $A$ ). Liver cell-conditioned medium gives poorer cholinergic induction than does heart or skeletal muscle cell-conditioned medium (Patterson and Chun, 1977). The induction of acetylcholine synthesis and the expression of C55 were compared in several different platings incubated for 3 weeks in these media (Table $I B$ ). Again there was a qualitative correlation between the acetylcholine/catecholamine ratio of neurotransmitter type and the expression of C55 consistent
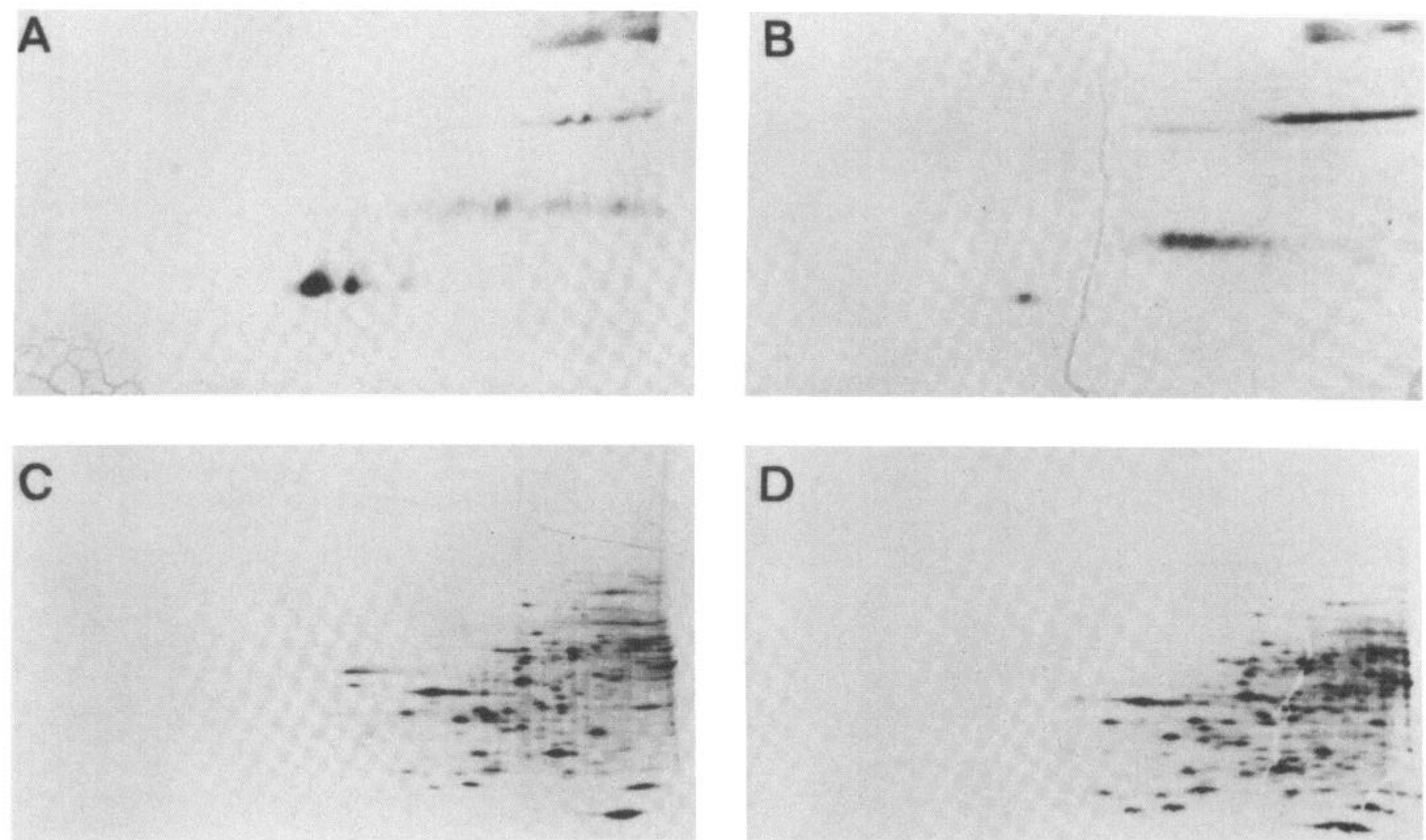

Figure 2. Two-dimensional gel analysis of basic proteins. Proteins labeled with $\left[{ }^{3} \mathrm{H}\right]$ fucose $(A$ and $B)$ or $\left[{ }^{3} \mathrm{H}\right] l$ leucine $(C$ and $D)$ were separated by nonequilibrium $\mathrm{pH}$ gradient electrophoresis followed by a second dimension in SDS. The top of the NEPHGE gel is at the right, but, as in Figure 1, the basic end of the gel is at the left and the acidic end is on the right. $A$ and $C$, Adrenergic neuronal cultures; $B$ and $D$, cholinergic neuronal cultures. 

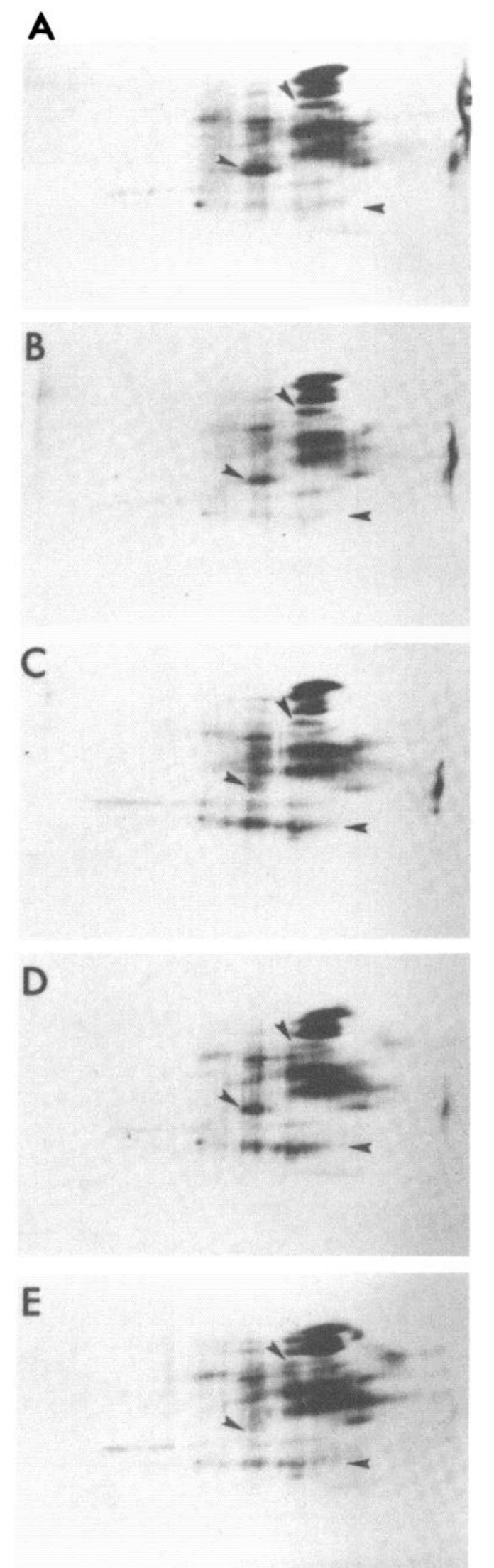

Figure 3. Butyric acid induces the expression of cholinergic glycoproteins. Isoelectric focusing/SDS two-dimensional gels are shown of cultures labeled with $\left[{ }^{3} \mathrm{H}\right]$ fucose after growth in (A) $20 \mathrm{~mm} \mathrm{~K}^{+}$medium, (B) unmodified L15 $\mathrm{CO}_{2}$ medium, $(C)$ with the interpretation that the two phenomena are linked.

Butyric acid has been shown by Walicke and Patterson (1981a) to enhance acetylcholine production and reduce catecholamine production by neurons grown in conditioned medium. We observed that $1 \mathrm{~mm}$ butyric acid alone significantly increased the ratio of acetylcholine/ catecholamine synthesized by the neurons (Table IC). Once again, the expression of C55, A155, and A82 was correlated with neurotransmitter choice, even when that choice was determined by a small molecule rather than by a high molecular weight biological factor. Growth in butyric acid depressed catecholamine synthesis below that seen in neurons grown in conditioned medium, and concurrently depressed the expression of A82 to very low or undetectable levels (Table IC and Fig. 3).

External accessibility of the glycoproteins. Since the negative charge of sialic acid residues can contribute significantly to the isoelectric point of glycoproteins, sensitivity to digestion by neuraminidase can be assessed by a basic shift in glycoprotein position on two-dimensional gels (Baumann and Doyle, 1979). Such a basic shift for a number of the glycoproteins labeled by the metabolic incorporation of $\left[{ }^{3} \mathrm{H}\right]$ fucose is shown in Figure 4. The isoelectric point of A155 is shifted by neuraminidase treatment of intact cells, while that of A82 is not. Labeling of the C55 belt disappeared in 6 out of 6 experiments when neurons were treated with neuraminidase, indicating that removal of sialic acid had such a dramatic effect on the isoelectric point or solubility of the molecule that it could no longer be visualized in this isoelectric focusing system. This extreme sensitivity to neuraminidase suggests that C55 is glycosylated with many sialic acid residues, an interpretation which is consistent with its marked charge heterogeneity.

Sialic acid residues were labeled by oxidation with sodium periodate followed by reduction with $\left[{ }^{3} \mathrm{H}\right] \mathrm{NaBH}_{4}$ (Fig. $5 A$ ). This technique labeled all of the proteins affected by neuraminidase treatment, including C55, confirming its sialic acid content. A number of proteins labeled by $\left[{ }^{3} \mathrm{H}\right]$ fucose but not affected by neuraminidase treatment, including A82, were not labeled with $\left[{ }^{3} \mathrm{H}\right] \mathrm{BH}_{4}$. In addition, glycolipids were labeled and migrated in the lower right (acidic) portion of the gel, and some very high molecular weight, heterogeneous material of unknown composition was seen at the upper left portion of the gel in a region where label from $\left[{ }^{3} \mathrm{H}\right]$ fucose was never seen.

Lactoperoxidase-catalyzed iodination of the cell surface at $0^{\circ} \mathrm{C}$ labeled $\mathrm{C} 55$ and $\mathrm{A} 155$ but not A82 (Fig. $5 B$ ). There were many quantitative differences in the intensity of labeling of various proteins when ${ }^{125} \mathrm{I}$ - and $\left[{ }^{3} \mathrm{H}\right]$ fucoselabeled cells were compared, but all of the major neuraminidase-sensitive proteins were accessible to lactoperoxidase as well.

The labeling of intact cultures with galactose oxidasecatalyzed oxidation of galactose and galactosamine resi-

medium containing $1 \mathrm{~mm}$ butyric acid, $(D) 50 \%$ heart cellconditioned medium, and $(E) 50 \%$ heart cell-conditioned medium plus $1 \mathrm{~mm}$ butyric acid. The arrowheads mark the positions of A155, A82, and C55; compare to Figure 1. 

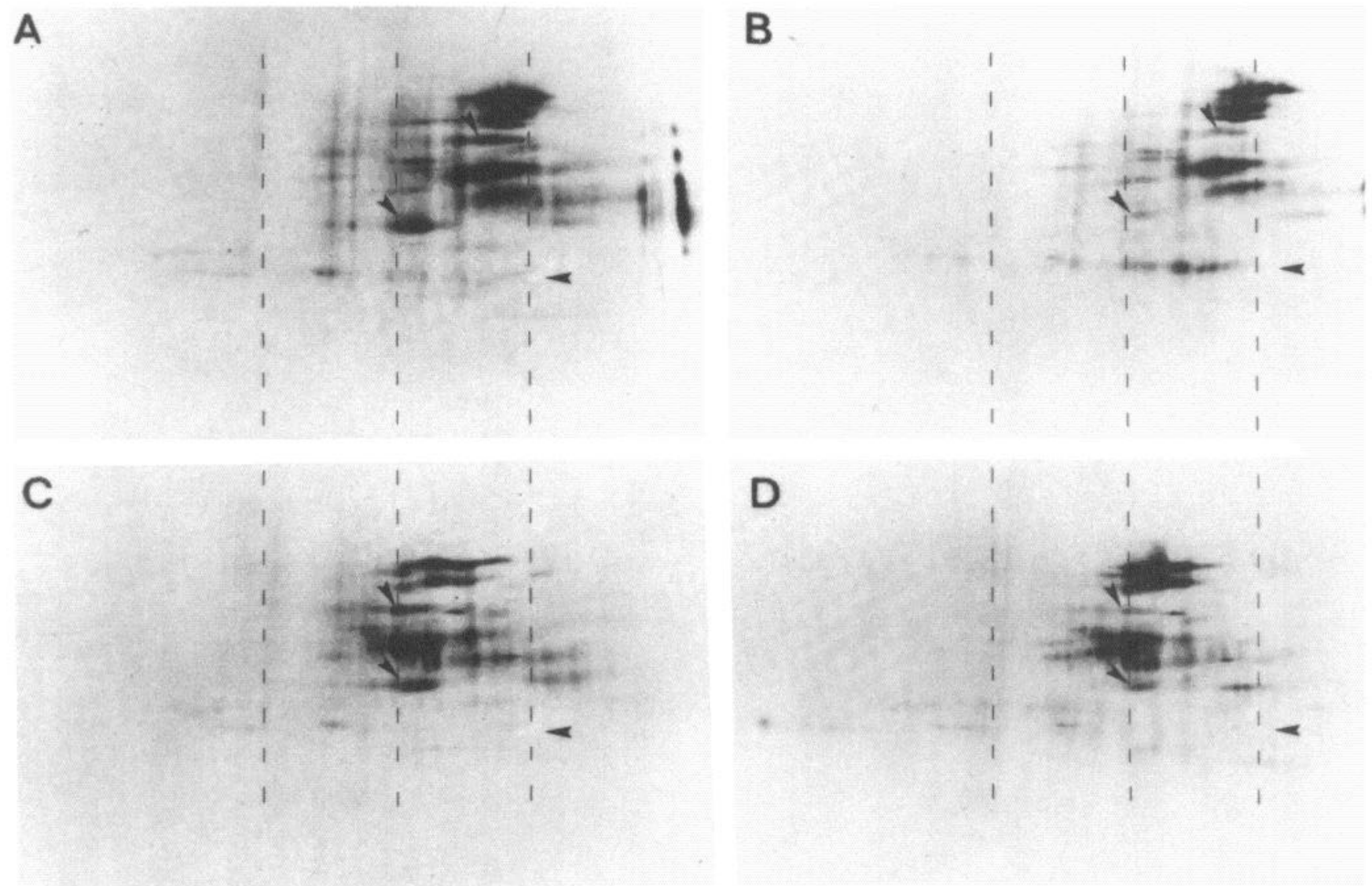

Figure 4. Neuraminidase sensitivity of neuronal glycoproteins. Adrenergic $(A$ and $C)$ and cholinergic $(B$ and $D)$ cultures were labeled with $\left[{ }^{3} \mathrm{H}\right]$ fucose, and their glycoproteins were separated on two-dimensional gels before $(A$ and $B)$ and after $(C$ and $D)$ treatment of intact cells with neuraminidase. Neuraminidase-sensitive proteins migrate to a more basic position (closer to the left). The positions of A155, A82, and C55 are marked by arrowheads as in Figures 1 and 3 . The dashed lines are added as a visual aid for comparing gels.

dues followed by $\left[{ }^{3} \mathrm{H}\right] \mathrm{NaBH}_{4}$ reduction, after exposing penultimate galactose and galactosamine residues with neuraminidase treatment, also confirmed the external accessibility of C55 and A155 and the inaccessibility of A82 (Fig. $5 C$ ). Only the one-dimensional SDS gel is shown because C55 disappears from two-dimensional gels after neuraminidase treatment whether $\left[{ }^{3} \mathrm{H}\right]$ fucose or galactose oxidase $/\left[{ }^{3} \mathrm{H}\right] \mathrm{BH}_{4}$ is used. The label at the apparent position of A82 is actually due to a more acidic glycoprotein of $M_{\mathrm{r}}=\sim 83,000$ (Fig. $1, A$ and $B$ ).

When the surface proteins of adrenergic and cholinergic cultures were compared after labeling by lactoperoxidase-catalyzed iodination, periodate $/\left[{ }^{3} \mathrm{H}\right] \mathrm{BH}_{4}$, or galactose oxidase $/\left[{ }^{3} \mathrm{H}\right] \mathrm{BH}_{4}$, the same differences in the amounts of A155 and C55 were seen as when the proteins were labeled by the incorporation of $\left[{ }^{3} \mathrm{H}\right]$ fucose. This indicates that the observed differences in expression reflect differences in the amount of protein present and not just differences in their rates of synthesis and turnover.

\section{Discussion}

These experiments demonstrate that the expression of certain major glycoproteins by cultured sympathetic neurons is correlated with the ability to synthesize and accumulate catecholamines or acetylcholine. The transition from an initial adrenergic state to a cholinergic state, which may occur in vivo in the subclass of sympathetic neurons innervating sweat glands (Landis and Keefe, 1980), is, in culture, under the control of a macromolecular factor released from heart cells (Patterson and Chun, 1977; Weber 1981). Unfractionated conditioned medium contains at least 60 glycoproteins secreted by the heart cells (K. J. Sweadner and K. Fukada, unpublished observation), and therefore, a critical question is whether the factor that induces the expression of cholinergic properties is the same factor that alters the labeling of $\mathrm{C} 55, \mathrm{~A} 155$, and $\mathrm{A} 82$. A rigorous answer awaits the purification of the factor(s) involved, but the present evidence indicates that the two phenomena are closely linked. There is a qualitative correlation between transmitter choice and protein expression when conditioned media from different sources are compared, and the effect can be mimicked by a small molecule, butyric acid. Butyrate has been observed to have a variety of effects on gene expression in other types of cultured cells, but there is as yet no consensus about its mechanism of action (Prasad and Sinha, 1976; Candido et al., 1978; Eisen et al., 1980; Via et al., 1980). Its effect on transmitter choice in the sympathetic neuron (to enhance cholinergic properties) is the opposite of the effect of dibutyryl cyclic adenosine $3^{\prime}, 5^{\prime}$-monophosphate (to enhance adrenergic properties) (Walicke and Patterson, 1981a). 

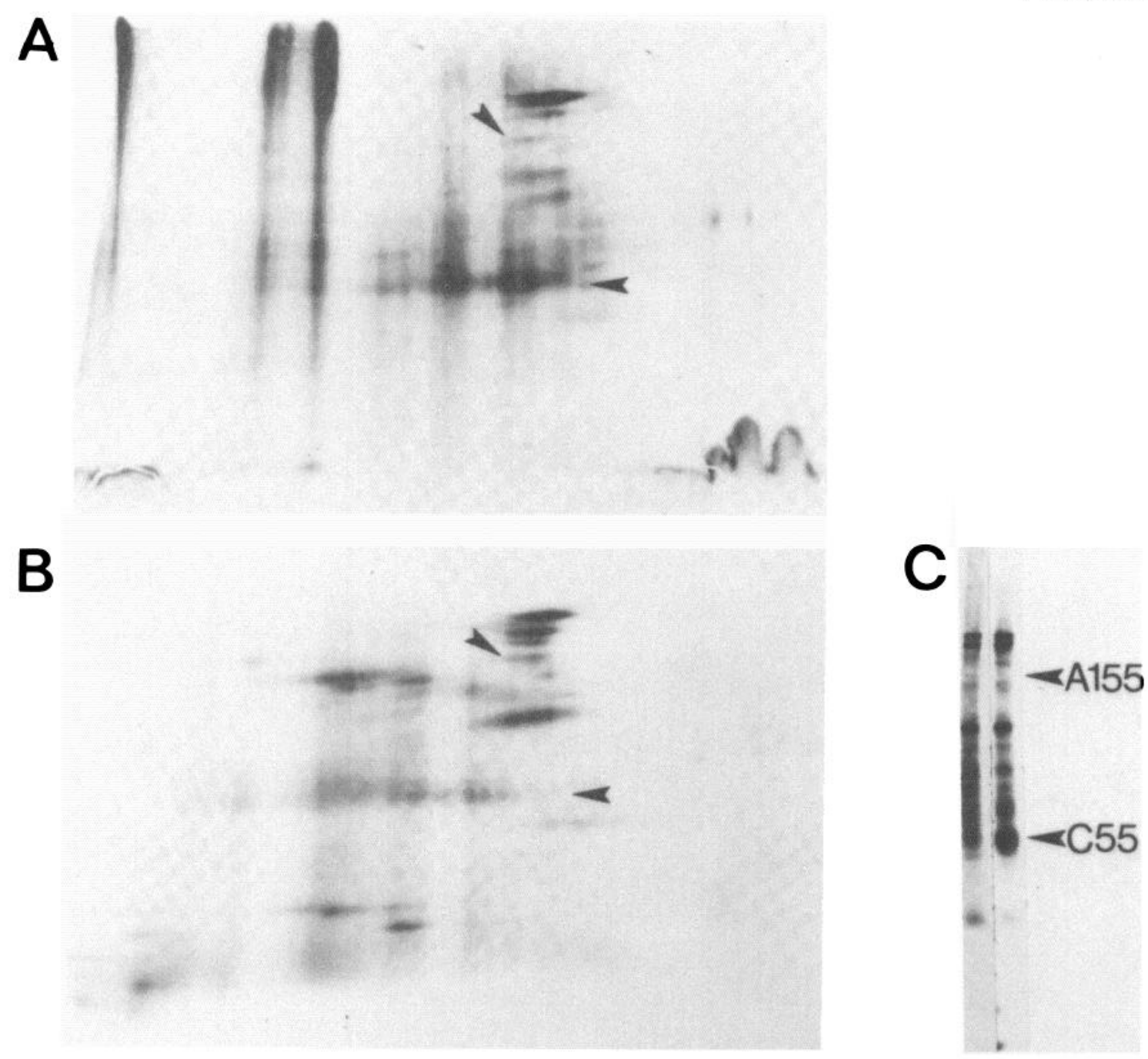

Figure 5. Periodate, lactoperoxidase, and galactose oxidase labeling of neuronal surface proteins. $A$, Two-dimensional gel of a cholinergic culture labeled with mild periodate oxidation of sialic acids followed by reduction with $\left[{ }^{3} \mathrm{H}\right] \mathrm{BH}_{4}$. $B$, Two-dimensional gel of a cholinergic culture labeled with lactoperoxidase/glucose oxidase-catalyzed iodination. $C$, One-dimensional SDS gel of adrenergic (left) and cholinergic (right) cultures labeled with galactose oxidase-catalyzed oxidation of galactose and galactosamine residues followed by reduction with $\left[{ }^{3} \mathrm{H}_{3} \mathrm{BH}_{4}\right.$. The positions of A155 and C55 are marked with arrowheads. A82 was not labeled detectably by any of the three procedures even in adrenergic cultures.

The difference in ratio of acetylcholine to catecholamine production ranges from 50 -fold to more than 1,000 fold in neurons grown in $20 \mathrm{~mm} \mathrm{~K}{ }^{+}$versus conditioned medium. The induction of cholinergic properties accounts for the larger fraction of this change in ratio, while the loss of adrenergic properties is proportionately smaller and slower. It has been demonstrated previously that the neurons retain some of their adrenergic properties, such as the ability to take up and store catecholamines, even in culture conditions that induce a large increase in acetylcholine production (Reichardt and Patterson, 1977; Wakshull et al., 1978; Landis, 1980; Higgins et al., 1981). It is not surprising, then, that the increase in the expression of C55 averages 250 -fold, while the decrease in the expression of A82 averages only 6.3-fold. In the presence of $1 \mathrm{~mm}$ butyric acid, which suppresses the expression of adrenergic properties, the decrease in the expression of A82 is to below detectable levels (Table IC and Fig. 3).
Neuraminidase, lactoperoxidase, and galactose oxidase are generally thought to have access only to proteins exposed on the cell surface (Hubbard and Cohn, 1976; Baumann and Doyle, 1979), although some active internalization of the enzymes cannot be ruled out for the reactions performed at or above room temperature. The data presented here are consistent with the interpretation that C55 and A155, as well as 10 to 12 other, unnamed proteins, are at least partly exposed on the exterior of the neuronal membranes. A82, on the other hand, is not detected on the cell surface of intact cells. It has been shown previously to co-migrate on two-dimensional gels with a glycoprotein which is secreted spontaneously into the culture medium (Sweadner, 1981), and its presence in homogenates of fucose-labeled cells most likely indicates the existence of an intracellular pool of protein awaiting secretion. The secreted A82, like the A82 seen in culture homogenates, is 2.5- to 4.5 -fold enriched in adrenergic over cholinergic cultures. After the 
neurons have been cultured for 3 weeks in $1 \mathrm{~mm}$ butyric acid, the secretion of A82 is suppressed to the same extent as its presence in homogenates of $\left[{ }^{3} \mathrm{H}\right]$ fucoselabeled cells, and this suppression does not require the continued presence of the butyrate during the isotopic labeling of the secreted protein (K. J. Sweadner, unpublished observation).

'The broad band of $M_{\mathrm{r}}=\sim 55,000$ that is induced in cholinergic conditions (C55) appears to be expressed as a single glycoprotein. The marked heterogeneity of its $\mathrm{pI}$ could be due to a variable extent of sialylation (Parham et al., 1974; Baumann and Doyle, 1979) or to partial aggregation of subunits during the isoelectric focusing in urea and NP 40, which would have the effect of retarding the mobility of the protein in the $4 \%$ acrylamide focusing gel. Interactions with ampholytes and $\mathrm{pH}$-dependent conformational transitions also have been proposed to account for the formation of multiple spots during the isoelectric focusing of single species of proteins (Cann et al., 1978). The disappearance of fucose-labeled C55 from the two-dimensional gel pattern after treatment with neuraminidase is most likely to be due to irreversible precipitation during the isoelectric focusing because the protein can still be detected on one-dimensional gels after neuraminidase treatment. C55 did not appear on the basic $\mathrm{pH}$ range NEPHGE gels after neuraminidase treatment, which argues that its disappearance from the isoelectric focusing/SDS two-dimensional gels is not simply due to a basic $\mathrm{pI}$ for the protein after it is stripped of sialic acid residues.

Estridge (1977) and Estridge and Bunge (1978) have previously labeled the glycoproteins and cell surface proteins of excised neurites of sympathetic neurons and analyzed them on one-dimensional SDS gels. The cultures had been grown in conditions which result in the expression of intermediate levels of cholinergic and adrenergic properties. It is difficult to state with confidence which bands seen in one SDS gel system correspond with those seen in another, but there is a notable difference between their results and ours. Estridge and Bunge (1978), using external labeling methods, found prominent labeling of two glycoprotein bands which co-migrate with tubulin $\left(M_{\mathrm{r}}=53,000\right.$ to 58,000$)$, while we did not. One might wonder if C55 is tubulin, but there are only very minor differences in the tubulin synthesized by adrenergic and cholinergic cultures (Sweadner and Gozes, 1980). In addition, tubulin purified by vinblastine precipitation migrates in the gel system used here to a significantly higher apparent molecular weight than does C55 and, on two-dimensional gels, has a more acidic pI (data not shown). Perhaps the excised and pelleted neurites labeled by Estridge (1977) did not reseal perfectly before the labeling procedures, permitting some local exposure of intracellular proteins. For example, a band which might be actin was labeled in the experiment shown in Figure 17 of Estridge and Bunge (1978). This is conjecture, however, and the discrepancies in the results need further consideration.

'The pheochromocytoma cell line, PC12, has a number of properties in common with sympathetic neurons, and its $\left[{ }^{3} \mathrm{H}\right]$ fucose- and glucosamine-labeled glycoproteins have been examined after growth in the presence and absence of nerve growth factor (McGuire et al., 1978). No spots obviously corresponding to C55 or A82 are seen in the two-dimensional gel pattern reported for $\mathrm{PC} 12$ cell glycoproteins, but the $M_{\mathrm{r}}=230,000$ glycoprotein (NILE) induced in PC12 in response to nerve growth factor has a mobility and molecular weight very similar to that of the most acidic, highest molecular weight glycoprotein seen in sympathetic neurons. Expression of this protein seems to be common to both adrenergic and cholinergic neurons.

The expression of three of the glycoproteins described here responds to factors secreted by certain non-neuronal cells and to butyric acid, conditions which affect the type of transmitter produced by the neurons. The correlation of glycoprotein expression and transmitter choice makes these glycoproteins attractive candidates for the mediation of intercellular communication specific for different kinds of neurons. Antibodies directed against these glycoproteins may be useful in the investigation of their functions.

\section{References}

Ames, G. F. -L., and K. Nikaido (1976) Two-dimensional gel electrophoresis of membrane proteins. Biochemistry 15: 616623.

Barondes, S. H. (1976) Neuronal Recognition, Plenum Publishing Co., New York.

Baumann, H., and D. Doyle (1979) Localization of membrane glycoproteins by in situ neuraminidase treatment of rat hepatoma tissue culture cells and two-dimensional gel electrophoretic analysis of the modified proteins. J. Biol. Chem. 254: 2542-2550.

Bonner, W. M., and R. A. Laskey (1974) A film detection method for tritium labelled proteins and nucleic acids in polyacrylamide gels. Eur. J. Biochem. 46: 83-88.

Bunge, R., M. Johnson, and C. D. Ross (1978) Nature and nurture in development of the autonomic neuron. Science 199: 1409-1416.

Candido, E. P. M., R. Reeves, and J. R. Davie (1978) Sodium butyrate inhibits histone deacetylation in cultured cells. Cell 14: $105-113$.

Cann, J. R., D. I. Stimpson, and D. J. Cox (1978) Isoelectric focusing of interacting systems. III. Carrier ampholyte-induced macromolecular association or dissociation into subunits. Anal. Biochem. 86: 34-49.

Chun, L. L. Y., P. H. Patterson, and H. Cantor (1980) Preliminary studies on the use of monoclonal antibodies as probes for sympathetic development. J. Exp. Biol. 89: 73-83.

Denburg, J. L. (1978a) The biochemistry of intercellular recognition. Adv. Comp. Physiol. Biochem. 7: 105-226.

Denburg, J. L. (1978b) Protein composition of cockroach muscles: Identification of candidate recognition macromolecules. J. Neurobiol. 9: 93-110.

Eisen, H., S. Hasthorp, R. Gjerst, S. Nasi, and F. Keppel (1980) Distribution and behavior of the chromosomal protein IP25 in vivo and tissue culture. In In Vivo and In Vitro Erythro poiesis: The Friend System, G. B. Rossi, ed., pp. 289-296, Elsevier-North Holland, Amsterdam.

Estridge, M. (1977) Polypeptides similar to the $\alpha$ and $\beta$ subunits of tubulin are exposed on the neuronal surface. Nature 268 . $60-63$.

Estridge, M., and R. Bunge (1978) Compositional analysis of growing axons from rat sympathetic neurons. J. Cell Biol. 79: $138-155$.

Frazier, W., and L. Glaser (1979) Surface components and cell 
recognition. Annu. Rev. Biochem. 48: 491-524.

Fukada, K. (1980) Hormonal control of neurotransmitter choice in sympathetic neurone cultures. Nature 287: 553-555.

Gottlieb, D. I., and L. Glaser (1980) Cellular recognition during neural development. Annu. Rev. Neurosci. 3: 303-318.

Hatton, M. W. C., and E. Regoeczi (1976) The proteolytic nature of commercial samples of galactose oxidase. Purification of the enzyme by a simple affinity method. Biochim. Biophys. Acta 438: 339-346.

Hawrot, E. (1980) Cultured sympathetic neurons: Effects of cell-derived and synthetic substrata on survival and development. Dev. Biol. 74: 136-151.

Hawrot, E., and P. H. Patterson (1979) Long-term culture of dissociated sympathetic neurons. Methods Enzymol. 58: 574584 .

Higgins, D., L. Iacovitti, T. H. Joh, and H. Burton (1981) The immunocytochemical localization of tyrosine hydroxylase within rat sympathetic neurons that release acetylcholine in culture. J. Neurosci. 1: 126-131.

Hubbard, A. L., and Z. A. Cohn (1972) The enzymatic iodination of the red cell membrane. J. Cell Biol. 55: 390-405.

Hubbard, A. L., and Z. A. Cohn (1976) Specific labels for cell surfaces. In Biochemical Analysis of Membranes, A. H. Maddy, ed., pp. 427-501, Chapman and Hall, London.

Laemmli, U. K. (1970) Cleavage of structural proteins during the assembly of the head of bacteriophage T4. Nature 227: $680-685$.

Landis, S. C. (1980) Developmental changes in the neurotransmitter properties of dissociated sympathetic neurons: A cytochemical study of the effects of medium. Dev. Biol. 77: 347-361.

Landis, S. C., and D. Keefe (1980) Development of cholinergic sympathetic innervation of eccrine sweat glands in rat footpad. Soc. Neurosci. Abstr. 6: 379.

Mains, R. E., and P. H. Patterson (1973) Primary cultures of dissociated sympathetic neurons. I. Establishment of longterm growth in culture and studies of differentiated properties. J. Cell Biol. 59: 329-345.

McGuire, J. C., L. A. Greene, and A. V. Furano (1978) NGF stimulates incorporation of fucose or glucosamine into an external glycoprotein in cultured rat PC12 pheochromocytoma cells. Cell 15: 357-365.

O'Farrell, P. H., and P. Z. O'Farrell (1976) Two-dimensional polyacrylamide gel electrophoretic fractionation. Methods Cell Biol. 16: 407-420.

O'Farrell, P. Z., H. M. Goodman, and P. H. O'Farrell (1977) High resolution two-dimensional electrophoresis of basic as well as acidic proteins. Cell 12: 1133-1142.

Parham, P., R. E. Humphreys, M. J. Turner, and J. L. Strominger (1974) Heterogeneity of HL-A antigen preparations is due to variable sialic acid content. Proc. Natl. Acad. Sci. U. S. A. 71 : 3998-4001.

Patterson, P. H. (1978) Environmental determination of auto- nomic neurotransmitter functions. Annu. Rev. Neurosci. 1: $1-17$.

Patterson, P. H., and I. I. Y. Chun (1977) The induction of acetylcholine synthesis in primary cultures of dissociated rat sympathetic neurons. I. Effects of conditioned medium. Dev. Biol. 56: 263-280.

Prasad, K. N., and P. K. Sinha (1976) Effect of sodium butyrate on mammalian cells in culture: A review. In Vitro $12: 125$ 132.

Reichardt, L. F., and P. H. Patterson (1977) Neurotransmitter synthesis and uptake by isolated sympathetic neurones in microcultures. Nature 270: 147-151.

Schwab, M., and S. C. Landis (1981) Membrane properties of cultured sympathetic neurons: Morphological studies of adrenergic and cholinergic differentiation. Dev. Biol. 84: 67-78.

Sweadner, K. J. (1981) Environmentally regulated expression of soluble extracellular proteins of sympathetic neurons. J. Biol. Chem. 256: 4063-4070.

Sweadner, K. J., and I. Gozes (1980) A single neuron expresses multiple forms of tubulin. Soc. Neurosci. Abstr. 6: 732.

Trisler, G. D., M. D. Schneider, and M. Nirenberg (1981) A topographic gradient of molecules in retina can be used to identify neuron position. Proc. Natl. Acad. Sci. U. S. A. 78: 2145-2149.

Van Lenten, L., and G. Ashwell (1971) Studies of the chemical and enzymatic modification of glycoproteins. A general method for the tritiation of sialic acid-containing glycoproteins. J. Biol. Chem. 246: 1889-1894.

Via, D. P., S. Sramek, G. Larriba, and S. Steiner (1980) Effects of sodium butyrate on the membrane glycoconjugates of murine sarcoma virus transformed rat cells. J. Cell Biol. 84: 225-234.

Wakshull, E., M. I. Johnson, and H. Burton (1978) Persistence of an amine uptake system in cultured sympathetic neurons which use acetylcholine as their transmitter. J. Cell Biol. 79: 121-131.

Walicke, P. A., and P. H. Patterson (1981a) On the role of cyclic nucleotides in the transmitter choice made by cultured sympathelic neurons. J. Neurosci. 1: 333-342.

Walicke, P. A., and P. H. Patterson (1981b) On the role of $\mathrm{Ca}^{2+}$ in the transmitter choice made by cultured sympathetic neurons. J. Neurosci. 1: 343-350.

Walicke, P. A., R. B. Campenot, and P. H. Patterson (1977) Determination of transmitter function by neuronal activity. Proc. Natl. Acad. Sci. U. S. A. 74: 5767-5771.

Weber, M. J. (1981) A diffusible factor responsible for the determination of cholinergic functions in cultured sympathetic neurons. Partial purification and characterization. J. Biol. Chem. 256: 3447-3453.

Zurn, A., and P. H. Patterson (1981) Globoside as a possible surface membrane receptor for the lectin soybean agglutinin in cultured sympathetic neurons. Soc. Neurosci. Abstr. 7: 847. 